\title{
Modulation of Lithium Disilicate Translucency through Heat Treatment
}

\author{
Seok-Ki Jung ${ }^{1,+} \oplus^{\circ}$, Dae Woon Kim ${ }^{2,+}$, Jeongyol Lee ${ }^{3}$, Selvaponpriya Ramasamy ${ }^{2}$, Hyun Sik Kim ${ }^{4}$, \\ Jae Jun Ryu ${ }^{5, *}$ and Ji Suk Shim ${ }^{3, *}$
}

check for

updates

Citation: Jung, S.-K.; Kim, D.W.; Lee, J.; Ramasamy, S.; Kim, H.S.; Ryu, J.J.; Shim, J.S. Modulation of Lithium Disilicate Translucency through Heat Treatment. Materials 2021, 14, 2094. https://doi.org/10.3390/ma14092094

Academic Editor: Lisa Biasetto

Received: 27 March 2021

Accepted: 20 April 2021

Published: 21 April 2021

Publisher's Note: MDPI stays neutral with regard to jurisdictional claims in published maps and institutional affiliations.

Copyright: (c) 2021 by the authors. Licensee MDPI, Basel, Switzerland. This article is an open access article distributed under the terms and conditions of the Creative Commons Attribution (CC BY) license (https:// creativecommons.org/licenses/by/ $4.0 /)$.
1 Department of Orthodontics, Korea University Guro Hospital, Seoul 08308, Korea; jgosggg@korea.ac.kr

2 Department of Medicine, Korea University Graduate School, Seoul 02841, Korea; damdeok28@daum.net (D.W.K.); dr.selvaponpriya@gmail.com (S.R.)

3 Department of Prosthodontics, Korea University Guro Hospital, Seoul 08308, Korea; wddc@korea.ac.kr

4 Korea Institute of Ceramic Engineering and Technology, Jinju-si 52851, Korea; hyunkim@kicet.re.kr

5 Department of Prosthodontics, Korea University Anam Hospital, Seoul 02841, Korea

* Correspondence: kopros@korea.ac.kr (J.J.R.); shoss@korea.ac.kr (J.S.S.)

+ These authors contributed equally to this work.

\begin{abstract}
The aim of this study was to present a control method for modulating the translucency of lithium disilicate ceramics through thermal refinement. Identical lithium disilicate blocks were thermally refined using four different heat treatment schedules, and the microstructure, translucency, and flexural strength of the ceramics were investigated in detail by SEM, spectroscopy, and a pistonon-three-ball test. The results showed that ceramics treated under higher heat had larger grains, with an average size between 240 and $1080 \mathrm{~nm}$. In addition, a higher transmittance of all wavelengths was observed in ceramics treated under lower heat, and the transmittance in the $550 \mathrm{~nm}$ wavelength ranged from 27 to $34 \%$. The results suggest that the translucency of ceramics can be modified through thermal refinement under two conditions: (1) the particle size of the ceramic is small enough to achieve minimal grain-boundary light scattering, and (2) the percentage of particles allowing visible light transmission is altered by the heat treatment.
\end{abstract}

Keywords: glass ceramics; grain size; optical properties; strength

\section{Introduction}

Lithium disilicate, which has a major crystalline phase of $\mathrm{Li}_{2} \mathrm{Si}_{2} \mathrm{O}_{5}[1]$, shows a typical microstructure where elongated crystals form an interlocking pattern [2,3]. Since lithium disilicate was first introduced as a dental restorative material by Ivoclar Vivadent, the material has been popular due to its favorable optical characteristics and high mechanical strength [4]. "Ingot-type" lithium disilicate has been used in the conventional dental fixed-restoration fabricating method known as the lost wax technique. Recently, with the advance of CAD/CAM (computer-aided design and computer-aided manufacturing) technology, a lithium disilicate block (IPS ${ }^{\mathrm{TM}}$ e.Max CAD) has been introduced for use in milling procedures. For easy milling, increased cutting efficiency, and minimal waste of milling tools, the lithium disilicate block is used in the intermediate state of crystallization $\left(\mathrm{Li}_{2} \mathrm{SiO}_{3}\right)$ [5], and additional thermal refinement processes are necessary after milling to enrich their crystallization [5].

Microstructure plays a major role in determining the translucency of ceramics, and this translucency can be modified by varying the volume, size, and density of crystals [6]. A fine-grained microstructure is desirable in order to improve the translucency in glass ceramics [6]. Ceramics with crystallites of a dimension smaller than the wavelength of light especially show improved translucency [7]. A microstructure with a high crystal density makes the ceramic less translucent as the light scattering is decreased [8,9]. Although the translucency of a ceramic can also be modified by adding pigments into the glass frit, the 
final results are more dependent on the phase composition and microstructure of the glass than on influences from a specific compound [5].

The microstructure of ceramics can be modified by adding chemical components or controlling the heat treatment $[10,11]$. Nucleating agents used for tailoring ceramic crystallization control both nucleation and crystal growth processes and determine the final shape, size, and contents of the crystal [12]; for example, $\mathrm{CaO}, \mathrm{P}_{2} \mathrm{O}_{5}$, and $\mathrm{CaF}_{2}$ all induce internal nucleation, and affect the morphology of crystals in lithium disilicate after heat treatment [13-15]. In high concentrations, nucleating agents cause the microstructure of lithium disilicate to become denser, and the crystals smaller and more spherically shaped [16]. On the other hand, $\mathrm{ZrO}_{2}$ is used to control phase composition by altering the crystallization kinetics that reduce the content of lithium metasilicate and hamper the growth of lithium disilicate [11]. Heat treatment is used to dissolve lithium metasilicate and to crystalize lithium disilicate [1]. Different heating parameters can change the driving force for dissolving lithium metasilicate and altering the overall phase composition [17,18]. Temperature is highly influential to glass viscosity and the mobility of molecules in ceramics; a high-temperature treatment causes low glass viscosity and high mobility of molecules in a ceramic and induces a coarsening process that facilitates crystal growth [19]. Holding time is related to the total energy applied to ceramics and increasing holding time during the nucleation stage causes an increased number of crystallites [19]. A controlled coarsening process during nucleation is achieved with an optimum nucleation duration to produce a fine-grained glass ceramic [20]. The heating schedule can be divided into a one- or two-stage process: the initial heat treatment critically acts to establish a setting for stabilizing lithium metasilicates, and the second heat treatment supplies the thermal energy to destabilize lithium metasilicate and induce the growth of lithium disilicate [1]. Previous studies have demonstrated that a two-stage heating schedule results in the formation of more and larger crystals than a single-stage heating schedule $[1,17,18,21]$.

In the present study, we used a controlled thermal refinement process to modulate translucency in lithium disilicate ceramics with a submicron-microstructure and evaluated the reliability of the method. The null hypothesis was that the translucency of lithium disilicate would not be modified by a controlled thermal refinement. In addition, we evaluated the effect of the altered substructure of lithium disilicate by thermal refinement on its translucency and mechanical properties.

\section{Materials and Methods}

\subsection{Specimen Preparation}

\subsubsection{Ceramic Block Preparation}

The glass batch $\left(72.6 \% \mathrm{SiO}_{2}, 10.7 \% \mathrm{Al}_{2} \mathrm{O}_{3}, 7.9 \% \mathrm{~K}_{2} \mathrm{O}, 2.1 \% \mathrm{CaO}, 0.3 \% \mathrm{TiO}_{2}, 4.7 \% \mathrm{Na}_{2} \mathrm{O}\right.$, $1.1 \%, \mathrm{Li}_{2} \mathrm{O}$, and $0.5 \% \mathrm{MgO}$; mol\%) was contained in a $100 \%$ Pt crucible (LT Metal, Seoul, Korea) and melted in an electric kiln (Fredrickson Kiln Co., Alfred, NY, USA) at $1316^{\circ} \mathrm{C}$ for $7 \mathrm{~h}$. Glass blocks fabricated from the batch were quenched in an air with the crucible and heat-treated for nucleation (Prototype, HASS Co., Gangneung, Korea).

\subsubsection{Heating Schedule}

Table 1 shows the summary of the heating schedule. The prepared glass blocks were labeled $815 \mathrm{~T}, 825 \mathrm{~T}, 840 \mathrm{~T}$, and $860 \mathrm{~T}$ according to the four different firing temperatures $\left(815{ }^{\circ} \mathrm{C}, 825^{\circ} \mathrm{C}, 840^{\circ} \mathrm{C}\right.$, and $860{ }^{\circ} \mathrm{C}$, respectively). They were then thermally refined in a furnace (Ivoclar Vivadent Programat, Ivoclar Vivadent AG, Schaan, Liechtenstein) as follows: after an initial standby duration of $3 \mathrm{~min}$ in $400{ }^{\circ} \mathrm{C}$, the temperature was increased to each firing temperature at a rate of $60^{\circ} \mathrm{C} / \mathrm{min}$. Holding time at each firing temperature was $15 \mathrm{~min}$, and the open temperature of the furnace head was $690^{\circ} \mathrm{C}$. 
Table 1. Heat treatment schedule.

\begin{tabular}{ccccccc}
\hline Groups & $\begin{array}{c}\text { Standby } \\
\text { Tempera- } \\
\text { ture } \\
\left({ }^{\circ} \mathbf{C}\right)\end{array}$ & $\begin{array}{c}\text { Standby } \\
\text { Duration } \\
(\mathbf{m i n})\end{array}$ & $\begin{array}{c}\text { Firing } \\
\text { Temperature } \\
\left({ }^{\circ} \mathbf{C} / \text { min) }\right.\end{array}$ & $\begin{array}{c}\text { Holding } \\
\text { Time } \\
(\mathbf{m i n})\end{array}$ & $\begin{array}{c}\text { Vacuum } \\
\text { on/off } \\
\text { Tempera- } \\
\text { ture } \\
\left({ }^{\circ} \mathbf{C}\right)\end{array}$ & $\begin{array}{c}\text { Furnace } \\
\text { Head } \\
\text { Open Tem- } \\
\text { perature } \\
\left({ }^{\circ} \mathbf{C}\right)\end{array}$ \\
\hline $815 \mathrm{~T}$ & 400 & 3 & 815 & 15 & $550 / 815$ & 690 \\
$825 \mathrm{~T}$ & 400 & 3 & 825 & 15 & $550 / 825$ & 690 \\
$840 \mathrm{~T}$ & 400 & 3 & 840 & 15 & $550 / 840$ & 690 \\
$860 \mathrm{~T}$ & 400 & 3 & 860 & 15 & $550 / 860$ & 690 \\
\hline
\end{tabular}

\subsection{Observation of Microstructure}

Five discs for each group were used for the observation of microstructure. The glassceramic specimens were mechanically polished using a $1 \mu \mathrm{m}$ diamond suspension and 4000grit $\mathrm{SiC}$ paper, and etched using $40 \%$ hydrofluoric acid. Each specimen was then coated with platinum in an ion coater (Eiko IB-5, Tokyo, Japan) for observation by scanning electron microscopy (SEM; Hitachi S-4500, Tokyo, Japan). Micrographs $\left(20,000 \times\right.$, area $\left.=30.1 \mu \mathrm{m}^{2}\right)$ were used to quantify the crystal number; average, minimum, and maximum crystal size; percentage of typical-sized particles using a digital image analyzing software package (ImageJ, NIH, Bethesda, MD, USA). Samples of glass-ceramics were chosen randomly from blocks before and after heat-treated at each temperature and pulverized for X-ray diffraction analysis (XRD). The specimens were placed in the holder of a Multi Flex X-ray diffractometer (Rigaku, Tokyo, Japan) using flat plate geometry. $\mathrm{Cu} \mathrm{K} \alpha$ radiation was used in the $2 \theta$ range of $10^{\circ}-60^{\circ}$, with a scanning rate of $2^{\circ} / \mathrm{min}$.

\subsection{Measurement of Optical Characteristics and Mechanical Properties}

\subsubsection{Visible Light Transmittance}

The ceramic discs were specially designed with set dimensions of $10 \mathrm{~mm}$ diameter by $1 \mathrm{~mm}$ thickness to best measure translucency. To evaluate the consistency of the translucency of the ceramics, multiple discs were prepared through separate thermal refinement processes. In total, 24 discs were prepared; six discs were allocated for each translucency. Since translucency is an optical property, it was evaluated using a spectrophotometer (UV2600; Shimadzu, Kyoto, Japan) using the transmittance mode at wavelengths of between 400 and $700 \mathrm{~nm}$.

\subsubsection{Biaxial Flexural Strength}

A piston-on-three-ball test (according to ISO 6872) [22] was performed to measure biaxial flexural strength. Ten ceramic discs for each group were prepared, with each disc having dimensions of $14 \mathrm{~mm}$ diameter by $1 \mathrm{~mm}$ thickness after preparation that included heat treatment, finishing, and polishing. The discs were positioned on a universal testing machine (AG-10kNX, Shimadzu Co, Japan) supported by three steel balls ( $3 \mathrm{~mm}$ diameter) positioned $120^{\circ}$ apart on a support circle (12 mm diameter). A flat punch-shaped rod (1.2 $\mathrm{mm}$ in diameter) with a crosshead speed of $1 \mathrm{~mm} / \mathrm{min}$ was used to place a load on the center of the specimens until a fracture occurred. The biaxial flexural strength in MPa was calculated from the peak load of failure.

\subsection{Statistical Analysis}

All data is shown as mean and standard deviation. To evaluate the statistical significance between the study groups, the Kruskal-Wallis test and post-hoc analysis using the Dwass-Steel-Critchlow-Fligner method were conducted. A $p$-value less than 0.05 was considered statistically significant. Statistical analyses were performed with SAS software (version 9.4; SAS Institute, Cary, NC, USA) [23]. To monitor the reliability of controlling ceramic translucency by thermal refinement, translucency results from six different specimens were evaluated using the intraclass correlation coefficient method with MedCalc 
statistical software (version 18; Ostend, Belgium) [24]. For assessing reliability between six specimens, the transmittance of each disc was repeatedly measured five times. The assessment of reproducibility of ceramic translucency by thermal refinement was evaluated through comparing the subjects from repeat measuring of six discs.

\section{Results}

\subsection{SEM Analysis}

Figure 1 presents the observed microstructures of the specimens. While $815 \mathrm{~T}$ exhibited a typical substructure consisting of fine, rounded particles, $825 \mathrm{~T}$ consisted of particles larger than those of $815 \mathrm{~T}$. Both $815 \mathrm{~T}$ and $825 \mathrm{~T}$ showed relatively uniform patterning of their particle arrays, while $840 \mathrm{~T}$ and $860 \mathrm{~T}$ showed irregular patterning of spherical and elongated particles. 860T exhibited more irregular patterning and contained larger and more elongated particles than $840 \mathrm{~T}$.
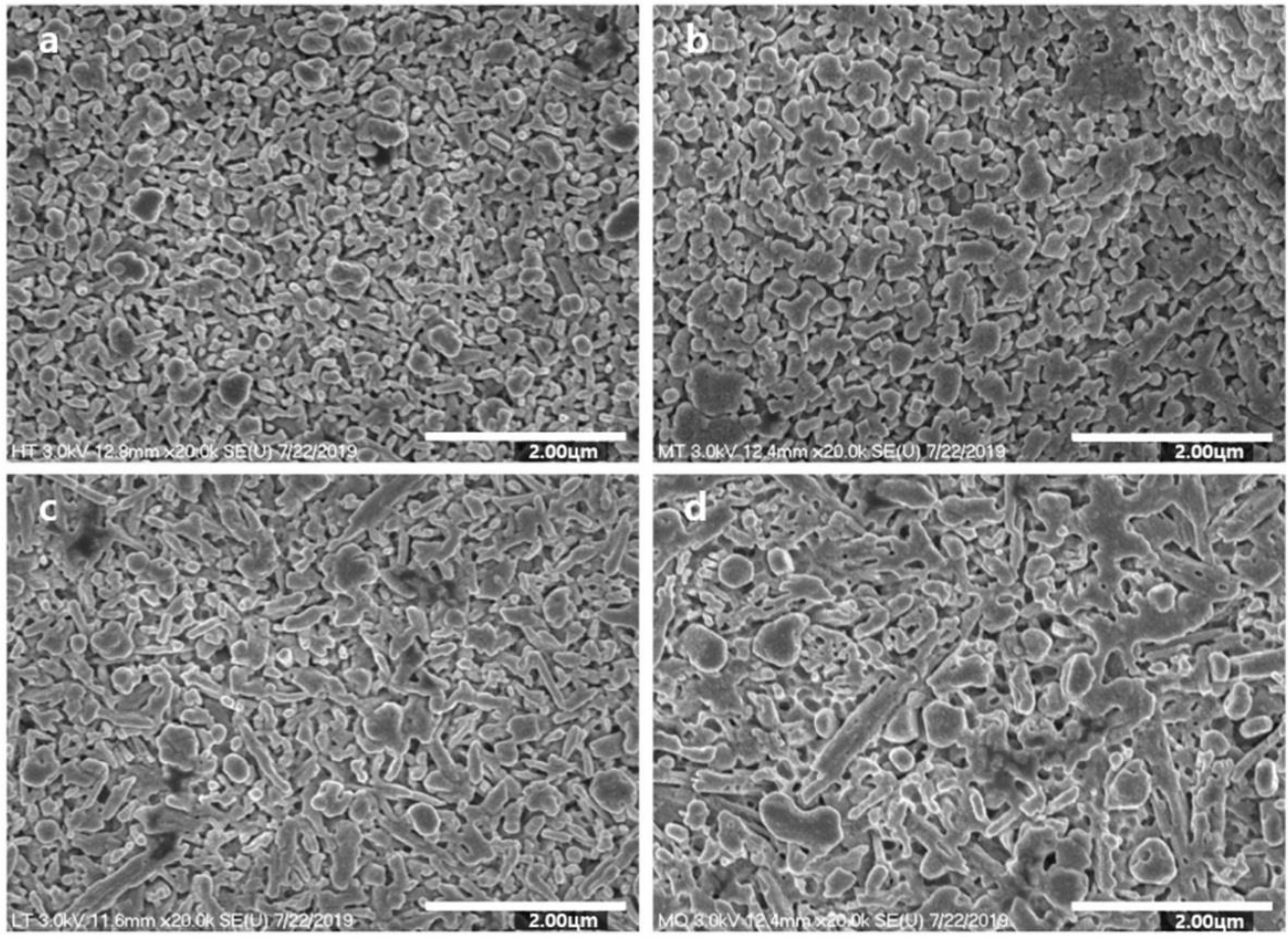

Figure 1. SEM photographs of lithium disilicate glass ceramics: (a) 815T, (b) 825T, (c), 840T, and (d) 860T. Original magnification $20,000 \times$.

Tables 2 and 3 summarize the crystallization data and particle size ratios for the microstructure analysis. The list of the specimens in the order of highest to lowest number of small particles is: $815 \mathrm{~T}, 825 \mathrm{~T}, 840 \mathrm{~T}$, and 860T; with the average size being 240, 500, 740, and $1080 \mathrm{~nm}$, respectively. All particles of $815 \mathrm{~T}$ were smaller than $400 \mathrm{~nm}$ in diameter, and those of $825 \mathrm{~T}$ were between 200 and $600 \mathrm{~nm}$. Nearly all particles (90.91\%) of 840T were between 200 and $800 \mathrm{~nm}$, while the remaining particles (9.09\%) were larger than $800 \mathrm{~nm}$. More than half of the particles (58.82\%) of $860 \mathrm{~T}$ were between 200 and $800 \mathrm{~nm}$, and the remaining particles $(41.17 \%)$ were greater than $800 \mathrm{~nm}$. 
Table 2. Crystallization data for the glass ceramics.

\begin{tabular}{ccccccc}
\hline \multirow{2}{*}{ Groups } & $\begin{array}{c}\text { Crystal Number } \\
\text { Mean (SD) }\end{array}$ & \multicolumn{4}{c}{ Crystal Size (nm) } & Distance between \\
\cline { 3 - 6 } & Mean & Min & Max & SD & Crystals (nm) \\
\hline $815 T$ & $2237.6(89.2)$ & 240 & 10 & 370 & 56.43 & $0.19 \pm 0.05$ \\
$825 \mathrm{~T}$ & $837.4(56.1)$ & 600 & 240 & 570 & 63.18 & $0.29 \pm 0.06$ \\
$840 \mathrm{~T}$ & $756.1(58.6)$ & 740 & 240 & 1450 & 167.25 & $0.34 \pm 0.09$ \\
$860 \mathrm{~T}$ & $330(14.2)$ & 1080 & 260 & 2760 & 584.36 & $0.43 \pm 0.14$ \\
\hline
\end{tabular}

SD; standard deviation.

Table 3. Ratio of typical particle size (nm) per unit area.

\begin{tabular}{cccccc}
\hline Groups & $<\mathbf{2 0 0}$ & $\mathbf{2 0 0 - 4 0 0}$ & $\mathbf{4 0 0 - 6 0 0}$ & $\mathbf{6 0 0 - 8 0 0}$ & $>\mathbf{8 0 0}$ \\
\hline $815 \mathrm{~T}$ & $71.88 \%$ & $28.12 \%$ & - & - & - \\
$825 \mathrm{~T}$ & - & $42.42 \%$ & $57.58 \%$ & - & - \\
$840 \mathrm{~T}$ & - & $15.15 \%$ & $51.52 \%$ & $24.24 \%$ & $9.09 \%$ \\
$860 \mathrm{~T}$ & - & $5.88 \%$ & $17.65 \%$ & $35.29 \%$ & $41.18 \%$ \\
\hline
\end{tabular}

\subsection{XRD Analysis}

A characteristic XRD pattern after each heat treatment is presented in Figure 2. The main crystalline phase was lithium disilicate, and the major peaks of the phase were observed at the $2 \theta$ values of 23.781, 24.341 and 24.841 . Blocks before heat treatment also showed the peak of lithium disilicate. Blocks treated with higher heat treatment showed higher peak of lithium disilicate. Cristobalite and lithium alumino silicate were shown as the secondary phases.

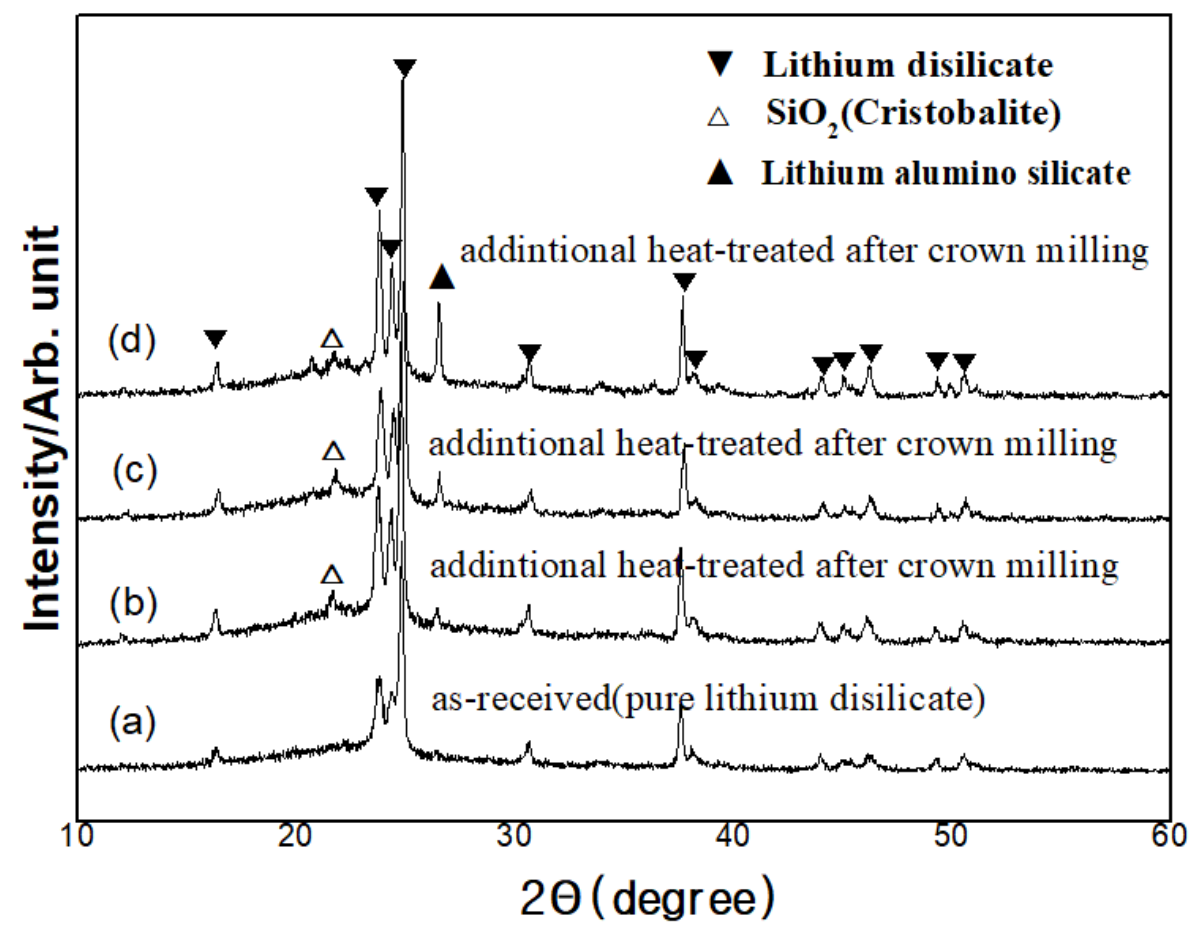

Figure 2. XRD of lithium disilicate glass ceramics: (a) glass-ceramic, (b) 815T, (c), 840T, and (d) 860T.

\subsection{Translucency}

Figure 3A shows the apparent translucency of each specimen and Figure 3B shows the spectra of light transmittance. Table 4 displays the light transmittance percentage along with the reliability of controlling the translucency of each ceramic. The highest transmittance of all wavelengths was observed in 815T, followed by 825T, 840T, and 860T. In the $550 \mathrm{~nm}$ wavelength, the transmittance of $815 \mathrm{~T}, 825 \mathrm{~T}, 840 \mathrm{~T}$, and $860 \mathrm{~T}$ were 34.03 , 
$32.65,31.82$, and 27.42 , respectively, while the intraclass correlation coefficients were 0.95 , $0.98,0.97$, and 0.97 , respectively.

(A)

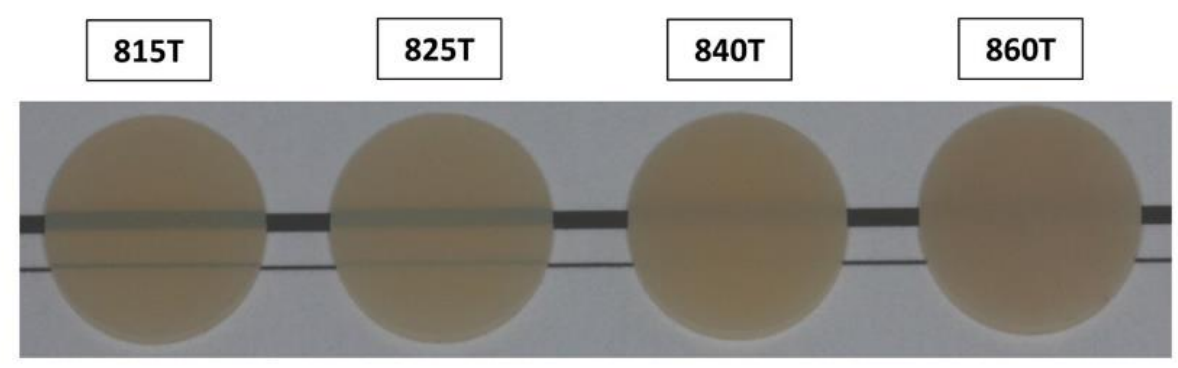

(B)

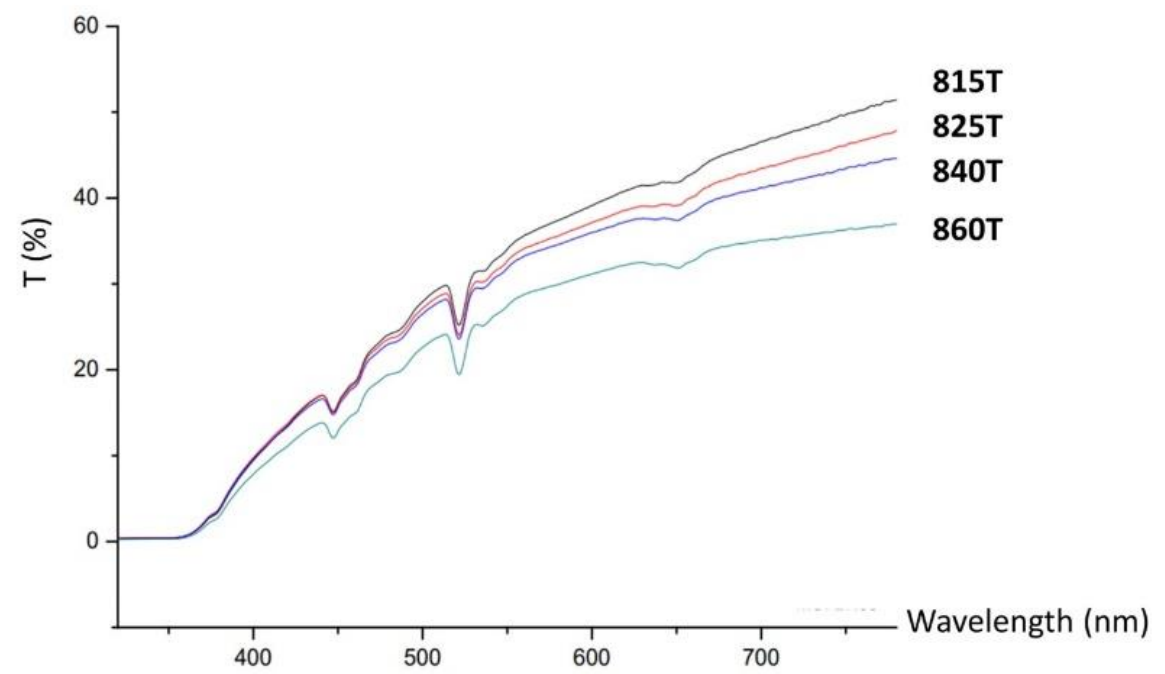

Figure 3. (A) Apparent translucency of ceramics. (B) Spectra of total light transmittance: the transmittance increased with the increase in light wavelength except at 450 and $530 \mathrm{~nm}$. $815 \mathrm{~T}$ was the most translucent group followed by 825T, 840T, and 860T.

Table 4. Light transmittance percentage and reliability of controlling translucency of each ceramic.

\begin{tabular}{|c|c|c|c|c|}
\hline Results & $815 \mathrm{~T}$ & $825 \mathrm{~T}$ & $840 \mathrm{~T}$ & $860 \mathrm{~T}$ \\
\hline $\begin{array}{l}\text { Light transmittance } \\
\text { percentage }(\%)^{*}\end{array}$ & $30.50 \pm 0.21^{d}$ & $27.58 \pm 0.38^{c}$ & $26.28 \pm 0.31^{b}$ & $22.20 \pm 0.38^{a}$ \\
\hline $\begin{array}{c}\text { Intraclass correlation } \\
\text { coefficient }^{+}\end{array}$ & 0.95 & 0.98 & 0.97 & 0.97 \\
\hline
\end{tabular}

* Groups with the same letter are not statistically different $(p>0.05) .{ }^{+}$The value of 1 means the highest reliability of translucency, a,b,c,d The small caps indicates the statistically relation between groups. The same letters indicate non-significant difference between sites $(p>0.05)$.

\subsection{Biaxial Flexural Strength}

Figure 4 presents the flexural strength of each group. In the piston-on-three-ball test, failure was considered to be reached when the specimens were fully broken. The highest flexural strength $(617.88 \mathrm{MPa})$ was observed in $825 \mathrm{~T}$, and the lowest flexural strength (403.19 MPa) in 860T, both with statistical significance. There was no statistical difference between 815T (536.72 MPa) and 840T (515.13 MPa) $(p>0.05)$. 


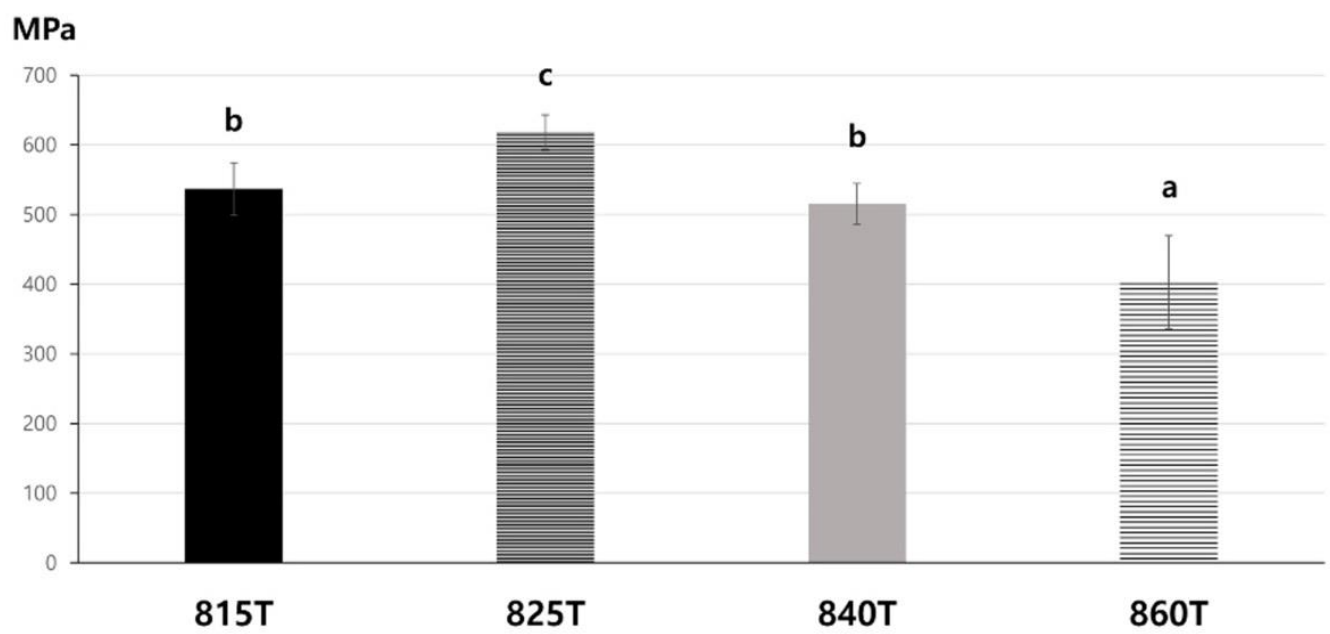

Figure 4. Flexural strength of the specimens in each group. Distinct letters indicate significant differences between groups. Groups with the same letter are not statistically different $(p>0.05)$. (a-d) The small caps indicate the statistically relation between sites. The same letters indicate non-significant difference between sites $(p>0.05)$

\section{Discussion}

Controlling translucency through the thermal refinement process is beneficial to CAD/CAM of lithium disilicates because one single block can be used for various clinical situations which require different levels of ceramic translucency. This is convenient since ceramics have to undergo thermal refinement during the CAD/CAM process. In this study, we evaluated the possibility of controlling translucency through thermal refinement. Through controlling heating parameters, ceramics with different translucencies with statistical significance were obtained. Therefore, the null hypothesis was rejected. In addition, high reproducibility in realizing each different translucency was shown (intraclass correlation coefficient values were above 0.95 ). Our results demonstrate that our method to modify the translucency of lithium disilicate through thermal refinement is efficient and reliable.

In addition, this study reliably demonstrates how translucency and flexural strength are modified by the alteration of the ceramic microstructure. The four different ceramics were materialized from blocks having identical components, and we altered the ceramic microstructures using heat treatment only. The ceramic blocks had completed nucleation through their initial heat treatment, and the additional thermal refinement modified the microstructure of the ceramics by affecting the process of crystallization according to the different temperatures. As noted in previous studies, a high temperature results in high mobility of molecules, low glass viscosity, and enhanced dislocation, thereby forming small crystal aggregates $[19,25]$. Thus, coarsening of the microstructure was observed on increasing the heat treatment temperature [26], and our findings were in agreement with this as the ceramics which were thermally refined at higher temperatures were composed of larger-sized particles.

Regarding translucency, many previous studies have shown modified translucency with supplemental materials such as $\mathrm{CaO}, \mathrm{P}_{2} \mathrm{O}_{5}, \mathrm{CaF}_{2}$, and $\mathrm{ZrO}_{2}$. In this study, for the first time, the translucency of ceramics was significantly modified with high reproducibility only by altering their microstructures. When light moves from air into a solid, it is reflected, absorbed, or transmitted. The light transmitted to a ceramic may experience the typical processes of reflection and refraction, termed "scattering" [27]. The light scattering is determined by the characteristics of ceramics including their impurities, pores, defects, and grain boundaries [27]. Relying on this diffuse-transmission mechanism, increasing the grain size is favorable to encountering a less-powerful light beam at the grain boundaries, thus causing minimal grain-boundary light scattering [28]. Another method to achieve low grain-boundary light scattering is by maintaining a smaller grain size relative to the 
wavelength of light [29]. The Rayleigh-Gans-Debye scattering model, a theoretical model to predict the desirable grain size of ceramics for obtaining high translucency, shows that a smaller particle size relative to the wavelength of incident light is more likely to cause elastic scattering [29]. From the Rayleigh approximation, $2 \pi \mathrm{r} n / \lambda$, where $\mathrm{r}$ is the radius of the grain, $\mathrm{n}$ is the refractive index, and $\lambda$ is the wavelength of light [27], considering that the average refractive index of lithium disilicate is 1.55 in the visible light spectrum [30], the maximum grain size required for Rayleigh scattering to transmit for visible light (wavelength between 370 and $750 \mathrm{~nm}$ ) is $483.87 \mathrm{~nm}$. In this study, 815T, 825T, 840T, and $860 \mathrm{~T}$ had grain sizes in the Rayleigh scattering ranges for visible light of $100 \%, 45 \%, 17 \%$, and $8 \%$, respectively. Overall, in spite of the small alteration in the size of ceramic particles through the coarsening process, there were definite differences between the compositions of grain sizes which critically affect the transmission of visible light.

In general, the mechanical properties of ceramic are affected by the crystal size [31], crystalline contents [32], and the irregularity of particles [33]. The ceramic composed of smaller particles shows better mechanical properties because the critical flaw size is proportional to the crystal size $[34,35]$. An increase in the crystalline content leads to improved mechanical properties of ceramics [36]. The ceramic composed with the particles of various size shows lower mechanical properties because irregular particle size induces stress, raising flaws, and breaking the interfacial interaction between the matrix and particles $[33,37]$. In this study, higher flexural strength was observed in the order of $825 \mathrm{~T}, 815 \mathrm{~T} / 840 \mathrm{~T}$, and $860 \mathrm{~T}$, and the mechanical properties were determined by the three factors. 825T showed the highest flexural strength which was composed of uniformly small particles with high crystallinity. While $815 \mathrm{~T}$ was composed of the uniformly small particles, it showed lower percentage of crystallinity than other groups. While 840T showed higher percentage of crystallinity, it was composed of irregular large particles. 860T comprised the most irregular and largest particles among the groups, and showed the lowest flexural strength.

The products of the method can be replicated for the commercial use of the control of translucency through thermal refinement. In this study, high reliability was obtained as shown by the intraclass correlation coefficient values of above 0.95 . The high repeatability may be due to the consistent content and crystal size during the materialization of lithium disilicate [38]. In addition, crystal growth is more stable through the two-stage heat treatment. However, a limitation of this study is that only a single furnace was used for thermal refinement; there may be subtle differences between different furnaces which may affect results. Future research using various kinds of furnaces may be beneficial to verify these results. In addition, in order to obtain more representative results, a greater number of measurements should be carried out in the future study. Energy Dispersive Xray Spectroscopy (EDS) was not carried out in this study. It might help to understand more clearly the cause of irregular strength behavior in the studied samples. Future research requires to consider these areas.

\section{Conclusions}

In this study, we verified a control method to modulate the translucency of lithium disilicate ceramics through thermal refinement processing after the milling process for a CAD/CAM of a ceramic block. The results of this study suggest that controlling the translucency of a ceramic through thermal refinement is possible under two conditions that (1) the particle size of the ceramic is small enough to achieve minimal grain-boundary light scattering, and (2) the percentage of particles allowing visible light transmission is altered by the heat treatment.

Author Contributions: Conceptualization, S.J. and D.K.; methodology, H.K. and J.S.; software, S.J. and H.K.; validation, D.K., J.L. and S.R.; formal analysis, J.R. and H.K.; investigation, S.J. and D.K.; resources, J.L.; data curation, S.R.; writing — original draft preparation, S.J. and D.K.; writing-review and editing, J.R. and J.S.; visualization, S.R.; supervision, J.L.; project administration, J.R. and J.S.; funding acquisition, J.S. All authors have read and agreed to the published version of the manuscript. 
Funding: This research was supported by the Basic Science Research Program through the National Research Foundation of Korea (NRF) funded by the Ministry of Education (2019R1A2C1089955).

Institutional Review Board Statement: Not applicable.

Informed Consent Statement: Not applicable.

Data Availability Statement: The data underlying this article will be shared on reasonable request from the corresponding author.

Conflicts of Interest: The authors declare no conflict of interest. The funders had no role in the design of the study; in the collection, analyses, or interpretation of data; in the writing of the manuscript, or in the decision to publish the results.

\section{References}

1. Zheng, X.; Wen, G.; Song, L.; Huang, X.X. Effects of P2O5 and heat treatment on crystallization and microstructure in lithium disilicate glass ceramics. Acta Mater. 2008, 56, 549-558. [CrossRef]

2. Albakry, M.; Guazzato, M.; Swain, M.V. Biaxial flexural strength, elastic moduli, and X-ray diffraction characterization of three pressable all-ceramic materials. J. Prosthet. Dent. 2003, 89, 374-380. [CrossRef]

3. Fischer, H.; Marx, R. Fracture toughness of dental ceramics: Comparison of bending and indentation method. Dent. Mater. 2002, 18, 12-19. [CrossRef]

4. Willard, A.; Gabriel Chu, T.M. The science and application of IPS e.Max dental ceramic. Kaohsiung J. Med. Sci. 2018, 34, 238-242. [CrossRef] [PubMed]

5. Fabian Fonzar, R.; Carrabba, M.; Sedda, M.; Ferrari, M.; Goracci, C.; Vichi, A. Flexural resistance of heat-pressed and CAD-CAM lithium disilicate with different translucencies. Dent. Mater. 2017, 33, 63-70. [CrossRef]

6. Beall, G.H.; Duke, D.A. Transparent glass-ceramics. J. Mater. Sci. 1969, 4, 340-352. [CrossRef]

7. Beall, G.H.; Pinckney, L.R. Nanophase Glass-Ceramics. J. Am. Ceram. Soc. 1999, 82, 5-16. [CrossRef]

8. Vichi, A.; Carrabba, M.; Paravina, R.; Ferrari, M. Translucency of ceramic materials for CEREC CAD/CAM system. J. Esthet. Restor. Dent. 2014, 26, 224-231. [CrossRef]

9. Anusavice, K.J.; Zhang, N.Z.; Moorhead, J.E. Influence of P205, AgNO3, and FeCl3 on color and translucency of lithia-based glass-ceramics. Dent. Mater. 1994, 10, 230-235. [CrossRef]

10. Huang, S.; Huang, Z.; Gao, W.; Cao, P. Trace phase formation, crystallization kinetics and crystallographic evolution of a lithium disilicate glass probed by synchrotron XRD technique. Sci. Rep. 2015, 5, 9159. [CrossRef]

11. Apel, E.; van't Hoen, C.; Rheinberger, V.; Holand, W. Influence of ZrO2 on the crystallization and properties of lithium disilicate glass-ceramics derived from a multi-component system. J. Eur. Ceram. Soc. 2007, 27, 1571-1577. [CrossRef]

12. Wang, F.; Gao, J.; Wang, H.; Chen, J.H. Flexural strength and translucent characteristics of lithium disilicate glass-ceramics with different P2O5 content. Mater. Des. 2010, 31, 3270-3274. [CrossRef]

13. Holand, W.; Rheinberger, V.; Apel, E.; van't Hoen, C. Principles and phenomena of bioengineering with glass-ceramics for dental restoration. J. Eur. Ceram. Soc. 2007, 27, 1521-1526. [CrossRef]

14. Sen, R.; Dutta, S.; Das, S.K.; Basu, S.K. Evaluation of a glass-ceramic coating for machine tool slides. Wear 1989, 130, 249-260. [CrossRef]

15. James, P.F.; Iqbal, Y.; Jais, U.S.; Jordery, S.; Lee, W.E. Crystallisation of silicate and phosphate glasses. J. Non Cryst. Solids 1997, 219, 17-29. [CrossRef]

16. Wen, G.; Zheng, X.; Song, L. Effects of P2O5 and sintering temperature on microstructure and mechanical properties of lithium disilicate glass-ceramics. Acta Mater. 2007, 55, 3583-3591. [CrossRef]

17. Borom, M.P.; Turkalo, A.M.; Doremus, R.H. Strength and Microstructure in Lithium Disilicate Glass-Ceramics. J. Am. Ceram. Soc. 1975, 58, 385-391. [CrossRef]

18. Albakry, M.; Guazzato, M.; Swain, M.V. Fracture toughness and hardness evaluation of three pressable all-ceramic dental materials. J. Dent. 2003, 31, 181-188. [CrossRef]

19. Chen, X.; Chadwick, T.C.; Wilson, R.M.; Hill, R.G.; Cattell, M.J. Crystallization and flexural strength optimization of fine-grained leucite glass-ceramics for dentistry. Dent. Mater. 2011, 27, 1153-1161. [CrossRef]

20. Hing, P.; McMillan, P.W. A transmission electron microscope study of glass-ceramics. J. Mater. Sci. 1973, 8, 340-348. [CrossRef]

21. Bischoff, C.; Eckert, H.; Apel, E.; Rheinberger, V.M.; Höland, W. Phase evolution in lithium disilicate glass-ceramics based on non-stoichiometric compositions of a multi-component system: Structural studies by 29Si single and double resonance solid state NMR. Phys. Chem. Chem. Phys. 2011, 13, 4540-4551. [CrossRef]

22. European Committee for Standardization. Dental Ceramic; ISO 6872; European Committee for Standardization: Brussels, Switzerland, 1998.

23. SAS Software, Version 9.4; SAS Institute Inc.: Cary, NC, USA, 2013.

24. MedCalc Statistical Software, Version 18; MedCalc Software bv: Ostend, Belgium, 2020.

25. Burgner, L.L.; Weinberg, M.C. An assessment of crystal growth behavior in lithium disilicate glass. J. Non Cryst. Solids 2001, 279, 28-43. [CrossRef] 
26. Denry, I.L.; Holloway, J.A. Effect of crystallization heat treatment on the microstructure and biaxial strength of fluorrichterite glass-ceramics. J. Biomed. Mater. Res. B Appl. Biomater. 2007, 80, 454-459. [CrossRef] [PubMed]

27. Zhang, Y. Making yttria-stabilized tetragonal zirconia translucent. Dent. Mater. 2014, 30, 1195-1203. [CrossRef]

28. Trunec, M.; Chlup, Z. Higher fracture toughness of tetragonal zirconia ceramics through nanocrystalline structure. Scr. Mater. 2009, 61, 56-59. [CrossRef]

29. Apetz, R.; van Bruggen, M.P.B. Transparent Alumina: A Light-Scattering Model. J. Am. Ceram. Soc. 2003, 86, 480-486. [CrossRef]

30. Ding, Y.; Jiang, S.; Luo, T.; Hu, Y.; Miura, Y.; Peyghambarian, N. Lithium disilicate crystalline slab waveguides from surface crystallised glass. Electron. Lett. 1999, 35, 504-505. [CrossRef]

31. Zhao, M.; Sun, Y.; Zhang, J.; Zhang, Y. Novel Translucent and Strong Submicron Alumina Ceramics for Dental Restorations. J. Dent. Res. 2018, 97, 289-295. [CrossRef] [PubMed]

32. Borba, M.; de Araújo, M.D.; Fukushima, K.A.; Yoshimura, H.N.; Cesar, P.F.; Griggs, J.A.; Della Bona, A. Effect of the microstructure on the lifetime of dental ceramics. Dent. Mater. 2011, 27, 710-721. [CrossRef]

33. Barreiro, M.M.; Riesgo, O.; Vicente, E.E. Phase identification in dental porcelains for ceramo-metallic restorations. Dent. Mater. 1989, 5, 51-57. [CrossRef]

34. Mackert, J.R., Jr.; Twiggs, S.W.; Russell, C.M.; Williams, A.L. Evidence of a critical leucite particle size for microcracking in dental porcelains. J. Dent. Res. 2001, 80, 1574-1579. [CrossRef]

35. Faber, K.T.; Evans, A.G. Crack deflection processes-I. Theory. Acta Metall. 1983, 31, 565-576. [CrossRef]

36. Denry, I.L.; Holloway, J.A. Elastic constants, Vickers hardness, and fracture toughness of fluorrichterite-based glass-ceramics. Dent. Mater. 2004, 20, 213-219. [CrossRef]

37. Liao, W.H.; Tien, H.W.; Hsiao, S.T.; Li, S.M.; Wang, Y.S.; Huang, Y.L.; Yang, S.Y.; Ma, C.C.; Wu, Y.F. Effects of multiwalled carbon nanotubes functionalization on the morphology and mechanical and thermal properties of carbon fiber/vinyl ester composites. ACS Appl. Mater. Interfaces 2013, 5, 3975-3982. [CrossRef]

38. Donald, I.W.; Metcalfe, B.L.; Wood, D.J.; Copley, J.R. The preparation and properties of some lithium zinc silicate glass-ceramics. J. Mater. Sci. 1989, 24, 3892-3903. [CrossRef] 